\title{
LEPROSY RELIEF AND CONTROL WORK IN TIRUKOILUR TALUK, SOUTH INDIA
}

\author{
V. EKAMBARAM, M.B.B.S. \\ and C. S. Ganghadara Sharma, M.B.B.S. \\ (Medical Officer in Charge and Assistant Surgeon respectively of \\ the Government Leprosy. Treatment and Study Centre, Tirukoilur).
}

\section{Introduction}

Many methods of control have been applied to leprosy, that oldest human disease, but still it remains a great problem in many underdeveloped countries. Ideas about the control of the disease have varied from century to century, but basically leprosy is a rural disease and control methods should be adapted to rural conditions. The aim of this paper is to present and discuss existing control methods of various countries and compare them with Indian methods, in particular with those used in this Centre, which is one of the major control units of the Government of India.

In the past the principles of leprosy control have been greatly influenced by irrational fear of leprosy. Methods tended to be drastic and inhuman, and the previous lack of an effective treatment tended to keep them so. The leprosy sufferer was treated as an outcaste and a danger to society, and was forced to live outside the village, dress differently, and announce himself as "unclean" when any "healthy" individual passed by. This cruel and unscientific attitude was not surprising in view of lack of knowledge of the disease, and it may have been effective in Europe in securing a measure of control. The discovery of the causal organism by Hansen the Norwegian leprologist in 1874 led to some improvement, since leprosy could now be regarded as one of the infectious diseases and potentially controllable. As there was still no known effective therapy, the emphasis on segregation continued, and during the 19th century this was mainly institutional segregation in "settlements". For lack of knowledge there was no effective propaganda to prevent the disease. Then in the latter part of the 19th century leprosy did come to be understood better and the first steps in classification were taken, and Muir enunciated his three principles of control, Propaganda, Treatment, and Survey (P.T.S.) and began to apply them in India. In many countries for some time segregation remained the main bulwark of control.

\section{Modern Consensus of Opinion about Leprosy Control}

This has been greatly modified by the coming of effective therapy by the sulphone group of drugs. After leprosy prevalence has been ascertained in a given area, and the environmental conditions studied, treatment facilities can be provided where needed, and we 
can start to use the sulphones as a method of control. The new treatment centres are placed carefully wherever needed, so that patients will not have to attend far from their homes. The control action of the sulphone treatment belongs to its power of gradually reducing the bacillary counts, and of late there has been a tendency to make treatment available sooner and more surely by placing the clinics where the patients live, that is, in the villages themselves. Furthermore, domiciliary treatment has been introduced. It has been possible also to improve propaganda because of the growth of our knowledge. Great stress is laid on the protection of children from infection, the importance of early treatment for leprosy, the importance of regularity in treatment, and the need for an enlightened attitude to leprosy.

(One of us, V.E., recently studied leprosy control units, by means of a WHO Fellowship, in Nigeria, Ceylon, Malaya, and Siam, and we propose to describe the working of our Tirokoilur Centre and then compare them with it).

\section{The Tirukoilur Centre}

This was established in South Arcot District in April 1955 as a major control unit under the principles of leprosy control enunciated by the Government of India. These principles recognized the anti-bacillary action of the sulphones and the use in control that could be made of it, and set up a number of pilot project areas for the application of intensive mass treatment and simultaneous health education about the infectivity of the disease and its prevention, inculcating a rational outlook on the disease and sympathy between patients and the healthy. It is hoped by this propaganda to overcome the tendency to conceal the disease. Each centre should cover a population between 40,000 and 50,000 in an effort to take the treatment to every patient and contact, if necessary by house to house visits. Two types of centre are proposed. In the Study and Treatment Centre treatment and health education will be joined to leprosy surveys by a special team using laboratory facilities, and trials of BCG will not be forgotten. On the other hand there will also be plain Treatment Centres.

Accordingly the Tirukoilur Centre founded in 1955 comprised four sections, (1) a Treatment Unit with staff of 2 medical officers, 2 nurses, 2 nursing orderlies, 2 compounders, 2 peons, 2 health inspectors, 2 menials; (2) a Survey Unit with staff of 1 health officer, 2 health inspectors, 2 peons; (3) A Laboratory Unit with staff of a pathologist medical officer, 1 technician, 2 menials; (4) an Administrative Unit with 5 clerks. There was a jeep for transport, with one driver. Later some of the staff posts were found to be unnecessary and the staff was reduced slightly.

The range of work was based on the former working area of a 
non-official leprosy organization called the Thakkar Bapu Kushta Nivaran Sangh. This area is on the north side of the River Penniar in Tirukoilur taluk, and comprises some 80 square miles (about 207 sq. kilom.) containing 54 villages and a total population of 65,290 . From the headquarters at Tirukoilur work extends to a maximum of 13 miles (about 22 kilom.) in all directions. Patients obtained from the area were 2,447 (456 lepromatous and 1,991 nonlepromatous) and in addition there were 1,767 patients treated from outside the project area, so the grand total amounted to 4,214. There were 6 outpatient clinics.

In its general plans the Tirukoilur Centre includes a leprosy survey and re-survey at 5 years of all villages in the area, and of some villages outside the area which will serve as controls at a time of evaluation. In the epidemiology attention will be paid to the number of new cases among contacts and non-contacts, any increase in the incidence of leprosy, the progress of patients who have been discharged from treatment, and the effect of migration and immigration on these villages. The main aim is to make treatment available to all patients by means of treatment centres in the villages and house distribution of the sulphones, with adequate records and follow-up. There is a 20 bed hospital attached to headquarters wherein complications and systemic and surgical conditions can be treated. Contacts are observed closely, and laboratory investigations are available at the headquarters laboratory.

The 6 clinics are sited in the zones of the area in such a manner that no patient need walk more than 3 miles to attend. Each clinic functions once a week. The treatment team of doctors, pharmacists, and nursing orderlies travels in a jeep carrying DDS and medicines for intercurrent illnesses, and ointments and dressings. Patients assemble at roadside villages according to a scheduled weekly programme; records are made of treatment and smears and photos taken as indicated. The treatment party thus covers a zone thoroughly and the minor general ailments of the local population are treated as required, which adds to the popularity of the specific campaign. The routine leprosy treatment used is oral DDS, with oral thiosemicarbazone for a few cases who do not tolerate DDS well.

Health Inspectors of the treatment unit have an important part to play. Any absentees are sought out in their homes on the following day by the two health inspectors, who find out the cause of absence and give the sulphones if the cause of absence was reasonable and unavoidable, such as ulceration or the demands of agricultural work. Each health inspector keeps a daily diary of his work which is read daily by the medical officer. Any patient found on these visits to be suffering from complications or an intercurrent disease can be sent to the hospital, which can deal with most of these as well as the surgery for acute neuritis, for gynaecomastıa, deformity requiring 
amputation, and other conditions. The health inspectors also have the oversight of contacts; they examine healthy contacts every 6 months. Registers are kept of all patients in the area and their contacts. If leprosy is detected in a contact, or any suspicious signs of it, he is sent at once to the medical officer for examination. Still another duty of the health inspectors is to oversee the leprosy patients who have been detected by the survey party and have failed to attend for treatment, and to encourage them to do so. During the regular visits to the villages, the treatment party as well as the health inspector do propaganda to the villagers about the nature of leprosy and how to prevent its spread, with special emphasis on how to protect children.

In the laboratory attached to the headquarters of the centre, smears, blood examinations and routine urine and stools examinations are done, but histopathology is not available as yet. The administrative unit looks after the office work and records and general matters connected with the centre. The general administration of the centre and the direction of the activities of the sections is in the hands of one of the assistant surgeons who is an experienced leprosy worker.

\section{Discussion of the Working of the Centre}

Certain practical advantages emerge in the above method of working. The method of giving treatment to the patients in their homes and villages is a satisfying alternative to the impossible task of providing institutional care for all patients in a heavily endemic area. Because the patients are not extracted from their homes and villages for treatment the problem of rehabilitation is rendered easier; it is a difficult one for institutional patients. The tendency to hide, so common where compulsory segregation is in force, is also counteracted by home treatment, and patients tend to come early in the disease. The cost of maintenance of the patients is saved and the working cost is much less than in the institutional method. There is no disruption of the family structure and social problems do not arise, such as when the patient is the breadwinner; nor is the stigma attached to the disease so noticeable in the home and village scheme as in the case of those segregated in an institution.

Some difficulties peculiar to this area have arisen. Most of the people have to work in the fields during the morning and best part of the day, and this hinders attendance. Their poverty also reacts on this, as many cannot afford loss of a day's wages once a week, and many employers are not willing to release them in the mornings which are the best for the field work. Poverty and undernourishment of many involves them in general ailments and in lepra reaction which damage their attendance. Injuries to the limbs from manual labour and field work, and subsequent infection, may afflict some, 
and lead on to mutilations. They may not attend hospital because of poverty and lack of transport. As most of the patients are illiterate and superstitious, there are some absences from the clinics because of the influence of various superstitions. In a country where doctors are few and specialist leprosy workers very few, quacks have a great opportunity. They promise quick and miraculous cures and lure many patients from attendance at the clinics. Quacks and a few antisocial persons may decry the prolonged treatment. DDS is available in the open market. A few rich patients occur, but for snobbish reasons fail to attend the clinics, and may take no treatment at all. Even among the poor there are some who reject advice and treatment, knowing that there is no compulsive law about it; this is a cause of worry to the leprosy workers. An analysis of the reasons for absence in a token sample of 100 patients, based on the report of the visits of health inspectors over 3 months, reveals the following:-

$\begin{array}{lllrr}\text { Agricultural work } \quad \ldots & \ldots & \ldots & \ldots & 169 \\ \text { General ailments and complications } & \ldots & 38 \\ \text { Temporary migration (to earn a living) } & \ldots & 65 \\ \text { Negligence (superstitions and ignorance) } & \ldots & 225 \\ \text { Under treatment by quacks and private doctors } & 30 \\ \text { Not willing to take treatment at clinics } & \ldots & 46\end{array}$

573 visits paid.

Certain administrative difficulties are worth reporting. The first is caused by the reluctance of all classes of hospital workers, even doctors, to work in the leprosy field. Those posted to it are usually unwilling workers, and there is no inducement in the shape of extra privileges of pay or leave. The medical officers of the centre are the only people trained in leprosy work so a heavier burden falls on them: they have to conduct the outpatient clinics daily and much of this routine work could be managed by non-medical workers if they were available. The medical officers are few in number and hence the area that can be controlled is limited.

\section{Comparison with Centres Abroad}

The senior author recently visited Nigeria, Ceylon, Siam, and Malaya as a WHO Fellow in leprosy control, and is able to report his comparative impressions as follow:-

Nigeria. Leprosy work is now being organızed on a mass scale in Northern Nigeria. The one medical officer at headquarters organizes and directs the entire leprosy control work with the help of specially trained non-medical people called leprosy inspectors and dispensary attendants. The local medical officer in each area supervises the dispensary attendants who carry out the routine leprosy treatment. The senior leprosy specialist, formerly the only medical specialist for leprosy (now, in 1958, there is a second) periodically 
visits the clinics to assess the progress of the cases and inspect the work of the non-medical personnel. Almost all the rural areas of Northern Nigeria now have leprosy outpatient clinics. It is the senior specialist who trains the dispensary attendants in leprosy work at the various hospitals, and the leprosy inspectors. I visited many of these clinics and found that they are well run. The number of patients treated by this system now reaches the remarkable total of 120,000 .

In Eastern Nigeria the control scheme was started many years ago and has had time to show perceptible effect. The special feature is that there is a leprosarium for each province which serves as a focus. The various outpatient clinics studding the province are managed by leprosy inspectors, who again are non-medical personnel who have been specially trained. The medical officers of the leprosarium visit the clinics periodically to watch the progress of the cases and examine the working of the clinics. Thus there is a uniform policy in the province because the leprosarium medical officers share in the central and the district work. Because non-medical personnel do the routine work of the clinics the medical officers are free for the more skilled work and for research. This method would su it India very well.

In Ceylon the incidence of leprosy is low and there are only about 3,000 cases. In Ceylon the special feature is that the care of leprosy patients in an area is the responsibility of the Public Health section of that area. The number of patients being few, individual attention can be paid to them: accurate registry is kept of them.

In Malaya there is no organized leprosy control work apart from a well equipped and first class leprosarium at Kuala Lumpur and another smaller one near Penang.

In Siam there is a huge leprosy problem, as in India, but UNICEF has come to their aid. There is a pilot project at Khon Kaen in Northeast Siam which is a field unit resembling our centre. It works on the same pattern as ours but has non-medical personnel specially trained in leprosy and called sanitarians, who carry on the routine work. The units are of two kinds, stationary and mobile. The stationary units are parts of the respective public health departments and a specially trained public health worker looks after the patients in the area, and domiciliary treatment is included. In the mobile unit there are various teams under charge of the sanitarians who travel to the various outpatient clinics. Here again a few medical officers with the help of non-medical personnel are able to look after the leprosy control work of the whole province. There are several leprosy settlements in Siam but the ideas of leprosy control represented by them have become obsolete. There are interesting "leprosy villages" in the country. I visited one such near Khon Kaen. The WHO officer who founded this village said "Instead of the 
patients being forced to stay in settlements which are almost prison camps these villages are ideal. Here many people who have leprosy come and settle down, take treatment from the Leprosy Pilot Project, and at the same time earn their livelihood by engaging in occupations suited to them, such as agriculture, carpentry, and cottage industries." This village is made up of a group of families from various parts of the province. Many stay in the village with their families of children. They are given weekly treatment by the staff of the pilot project. Cultivable lands are made available to them. They seemed quite happy, but I do not recommend this method, for various reasons. There is the same disruption of the social structure as in going to a settlement. They leave their homes, and this would not be popular in India. The control of leprosy by this method has the weakness that children stay with their parents and mix freely with other patients. This is a serious matter, in spite of the fact that preventive DDS is given to the children. Leprosy villages if applied on a mass scale in India would cause endless difficulties over land acquisition in an overpopulated country, and in fact would be impossible. Leprosy villages also add to the financial burden on the state, and the stigma of living in a specified place is similar to that of living in an institution.

Mention should be made of night segregation as advocated by Dr. R. G. Cochrane in India. This was based on the fact that many patients are only in contact with their children during the night, owing to being away on field labour most of the day. Segregation of infectious patients at night would go a long way in the control of the disease. I agree in principle with this method but fear it will not succeed in practice, because considerations of caste and social differences in our villages will hinder it too much.

\section{Conclusion}

We have described the methods and ideas of leprosy control current in South India and some other countries visited by the senior author. From our experience as leprosy workers we think the problem of leprosy control can only be solved if it is tackled along with other village problems and not as an isolated entity. Above all the disease can be controlled only if the state, the public, and the patients cooperate with the medical authorities. We reserve for a future date the assessment of the progress of the work of this centre.

\section{Acknowledgment}

We are grateful to Dr. K. Ramanujan, M.B.B.S., Silver Jubilee Children's Leprosy Clinic, Saidapet, Madras, for his valuable guidance and help in preparing this article. 


\section{Appendix}

(1) Summary of Survey Results in Pilot Project Area:

Number of villages served by the Centre...

Population of these villages ...

Total number of leprosy cases detected ... 2,447

Average gross incidence of each village (lem. 456; non-leprom 1,991)

Average open case rate of each village $\quad 17.8$

(2) Summary of the Work of the Tirukoilur Centre:

Number of outstation clinics

Total number of known cases in the area 2,869

Total number of patients under treatment in pilot area 2,447 (leprom. 456; non-leprom. 1,991)

Number of cases under treatment who originate outside the area 1,767

$$
\text { Grand total } \quad 3,870
$$

Number of healthy contacts under observation $\quad 10,688$

Average number of patients treated at all the six clinics per week 1,656

\section{Results}

1955: 1,071 patients on roll at beginning of year.

768 fresh cases registered during the year. No lapsed cases.

1,839 patients at end of year.

No cases with resolution of lesions.

No lepromatous cases who became negative.

1956: 1,839 cases at beginning of year.

824 fresh cases.

321 lapsed cases or migrated.

2,342 cases at end of year.

59 cases with resolution of lesions.

80 lepromatous cases who became negative.

1957: 2,342 cases at beginning of year.

250 fresh cases.

704 lapsed cases or migrated.

1,888 cases at end of year.

94 cases with resolution of lesions.

72 lepromatous cases who became negative. 